\title{
Retraction Note: Coastal climate environment and collaborative innovation of urban supply chain based on GIS
}

\author{
Yong $\mathrm{He}^{1}$
}

Published online: 22 November 2021

C) Saudi Society for Geosciences 2021

Retraction Note: Arabian Journal of Geosciences (2021) 14: 1384

https://doi.org/10.1007/s12517-021-07622-1

The Editor-in-Chief and the Publisher have retracted this article because the content of this article is nonsensical. The peer review process was not carried out in accordance with the Publisher's peer review policy. The author has not respond to correspondence regarding this retraction.

The original article can be found online at https://doi.org/10.1007/ s12517-021-07622-1.

Yong $\mathrm{He}$

heyong199880@163.com

1 Management School, Guilin University of Aerospace

Technology, Guilin 541004, Guangxi, China 